\title{
Surgical Site Infection Rates are Higher Among Colorectal Surgery Patients Receiving Non-penicillin Based Antibiotic Prophylaxis: A Retrospective Chart Review
}

\author{
AR. Fernandes', M. Valencia', S. Lethbridge', F. Farrokhyar', C. Eskicioglu', W. Ciccotelli3,4, SS. Forbes' \\ 'Division of General Surgery, Department of Surgery, McMaster University, Hamilton, Canada \\ ${ }^{2}$ Office of Surgical Research Services, Department of Surgery \& Department of Health, Evidence \& Impact, McMaster University, Hamilton, Canada \\ ${ }^{3}$ Department of Pathology \& Molecular Medicine, McMaster University, Hamilton, Canada \\ ${ }^{4}$ Department of Infection Prevention and Control, Grand River and St. Mary's Hospitals, Kitchener, Canada
}

\section{INTRODUCTION}

Elective colorectal procedures are associated with surgical site infections (SSI) in $4-17 \%$ of cases. The gold standard antibiotic prophylaxis is penicillin-based (PBAP). Standard regimens include cefazolin or ceftriaxone with metronidazole. For the $\mathrm{I}$ in 10 patients claiming penicillin allergy, several alternative antibiotic prophylaxis (AAP) regimens are offered in guidelines, however little evidence supports the equivalent efficacy of AAP. Regimens include ciprofloxacin plus metronidazole, clindamycin or tobramycin plus metronidazole, vancomycin plus metronidazole, clindamycin plus gentamycin, or gentamycin plus metronidazole.

\section{PURPOSE}

To determine if there is a difference in the incidence of postoperative SSI rate among elective colorectal surgery patients receiving $\mathrm{PBAP}$ as compared with those who receive $\mathrm{AAP}$.

\section{OUTCOME}

The difference in 30 day post-operative SSI rates between patients receiving PBAP vs AAP.

\section{METHODS}

Retrospective chart review of 967 adult elective colorectal rocedures completed at Hamilton Health Sciences Corporation between 2009-20I5. Eligible patients underwent elective clean contaminated procedures and received antibiotic prophylaxis. Emergent or urgent cases, and dirty wounds were excluded. REDCap Software was used for data collection.

Categorical variables were reported as counts and percentages and compared with chi-squares or Fisher's exact test. Continuous variables were reported as mean and standard deviation, or median with minimum and maximum, and compared with T-tests for independent samples or Mann-Whitney U-test. Univariable analyses were performed to identify candidate variables to include in the multivariable logistic regression (MLR) model. Candidate variables with $p \leq 0.10$ were included in the MLR. Odds ratios and $95 \%$ confidence intervals and $p$-vaues were reported. $A$ $\mathrm{p}$-value of 0.05 was set for statistical significance.

\section{RESULTS}

- No differences in baseline characteristics between groups

- $86.6 \%$ (837) received PBAP and $13.4 \%$ (130) received AAP

- SSI occurred in $16.2 \%$ of patients (I57)

\begin{tabular}{|l|l|}
\hline PREDICTORS OF SSI RISK & $\begin{array}{l}\text { Odds ratio }(95 \% \\
\text { confidence interval })\end{array}$ \\
\hline PBAP vs AAP & $0.63(0.40-0.99)$ \\
\hline BMI $>30$ & $1.72(1.20-2.50)$ \\
\hline ASA 3 \& 4 class & $2.35(1.05-5.26)$ \\
\hline Planned open surgery & $3.35(1.78-6.30)$ \\
\hline
\end{tabular}

\begin{tabular}{|l|l|l|}
\hline \multicolumn{1}{|c|}{$\begin{array}{c}\text { SERVICES USED WHEN SSI } \\
\text { ACQUIRED }\end{array}$} & $\begin{array}{l}\text { SSI } \\
\text { N=157 }\end{array}$ & $\begin{array}{l}\text { \% SSI pts } \\
\text { requiring } \\
\text { service }\end{array}$ \\
\hline $\begin{array}{l}\text { Required CCAC for } \\
\text { management of SSI }\end{array}$ & 75 & $47.8 \%$ \\
\hline $\begin{array}{l}\text { MD visit (ER, clinic) prior to } \\
\text { planned post-op }\end{array}$ & 61 & $38.9 \%$ \\
\hline $\begin{array}{l}\text { Re-admission for management } \\
\text { of SSI }\end{array}$ & 48 & $30.6 \%$ \\
\hline $\begin{array}{l}\text { Re-intervention for } \\
\text { management of SSI }\end{array}$ & 17 & $10.8 \%$ \\
\hline $\begin{array}{l}\text { Post-operative length of stay } \\
\text { (LOS) in days: Mean (SD) }\end{array}$ & $6(27.4)$ & $8(29.7)$ \\
\hline
\end{tabular}

\section{LIMITATIONS}

- Retrospective chart review, cannot conclude causation.

- Generalizability beyond elective colorectal surgery uncertain.

- Timing of antibiotic administration data incomplete.

\section{CONCLUSIONS}

PBAP and AAP regimens may not confer equivalent efficacy in preventing SSI in patients undergoing elective colorectal surgery. AAP in elective colorectal surgery patients is associated with a greater risk of SSI than PBAP.

SSI may be associated with longer post-operative LOS, as well as more MD visits, CCAC resource use, re-admissions and reinterventions.

Given these findings, more accurate penicillin allergy testing and reporting is necessary. In order to decrease SSI rates in elective colorectal surgery patients, all eligible patients should receive PBAP, and only truly penicillin-allergic patient should receive AAP.

\section{NEXT STEPS}

Prospective study: implement a point-of-care penicillin allergy test at the pre-operative patient visit. Patients testing negative for penicillin allergy will be ordered to receive the PBAP regimen, and only truly allergic patients will receive AAP. SSI rates pre- and post- study will then be compared.

\section{ACKNOWLEDGEMENTS}

- Regional Medical Associates Research Scholarship

- J. Sawires, N. Jedrzejko, E. Lovell, E. Gardiner

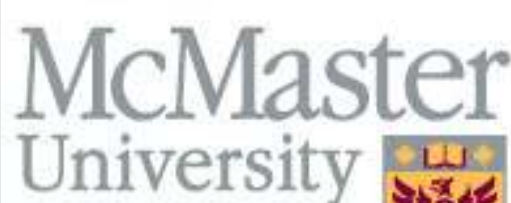
HELTH SCIENCES 